\title{
Investigating the nature of aspirated stops in Western Andalusian Spanish
}

\author{
Francisco Torreira \\ Max Planck Institute for Psycholinguistics, \\ The Netherlands \\ Francisco.Torreira@mpi.nl
}

In Western Andalusian Spanish (WAS), [h + voiceless stop] clusters are realized as long pre- and postaspirated stops. This study investigates if a new class of stops (realized as geminates with variable degrees of pre- and postaspiration) has emerged in this dialect, or if postaspiration in these clusters results from articulatory overlap. An experiment was carried out in which WAS speakers produced [h + voiceless stop] clusters under changes in speech rate and stress location. The duration of postaspiration, measured as voice onset, did not show systematic effects of any of the experimental variables. Moreover, trade-offs were observed between voice onset and preaspiration plus closure durations. These results indicate that postaspiration in WAS [ $\mathrm{h}+$ voiceless stop] clusters is the consequence of extensive articulatory overlap. It is further hypothesized that the lengthening of closures in WAS stops preceded by $[\mathrm{h}]$ results from a different gestural mechanism affecting all $[\mathrm{hC}]$ clusters in this dialect. From a broader perspective, since extensive overlap and consonantal lengthening do not occur in the $[\mathrm{hC}]$ clusters of other Spanish varieties, these findings lend support to the idea that intergestural coordination patterns can be dialect-specific.

\section{Introduction}

\subsection{Aspirated [s], aspirated stops in Western Andalusian Spanish, and purpose of this research}

In many dialects of Spanish, in both Europe and Latin America, syllable-final /s/ is often pronounced as a period of glottal frication or breathy voicing, a phenomenon that has come to be known in the literature as /s/-aspiration (Lipski 1994, Hualde 2005). The realization of $/ \mathrm{s} /$-aspiration in the western variety of Andalusian Spanish studied in this article is often described as a simple replacement of [h] for syllable-final /s/, as in pasta [pahta] 'pasta'. However, more detailed descriptions (e.g. Zamora Vicente 1969, Romero 1995a, Torreira 2007a) have noted a wider range of variation in the phonetic realization of this weakening phenomenon. In utterance-final position /s/ is generally elided: gatos [gato] 'cats'; in wordfinal position before a vowel, [h] is commonly heard: los otros [lohotro] 'the others'; in preconsonantal position, aspirated /s/ is coarticulated in different ways with the upcoming consonant: gemination is said to occur in the environment of nasals, laterals, and other fricatives: los martes [lom:arte] 'on Tuedays', los lunes [loliune] 'on Mondays' and las 
flores [laf:lore] 'the flowers', respectively; in front of voiced stops, aspiration leads to long voiced fricatives: los gatos [loy:ato] 'the cats'. As noted by Romero (1995b), this variation indicates that the phonetic realization of /s/-aspiration in Western Andalusian Spanish (WAS) is in fact more complex than suggested by a simple segmental rule (i.e. $/ \mathrm{s} />[\mathrm{h}]$ ).

This article deals with the realization of /s/-aspiration in yet another preconsonantal context, namely before a voiceless stop. Recent studies have shown that WAS aspirated /s/ plus voiceless stop clusters are realized as long voiceless stop closures variably preceded and followed by breathy voicing or aspiration (Torreira 2007a, b; O'Neill 2009). This phonetic pattern is unusual in the sense that postaspirated stops have not been reported to occur in any other dialect of Spanish, and more generally because of the co-occurrence in the same stop of both pre- and postaspiration, a rare phenomenon reported in the literature only for some Nordic dialects (see e.g. Helgason \& Ringen 2008, for Central Standard Swedish). More particularly, we investigate whether the occurrence of postaspiration in WAS voiceless stops results from extensive coarticulation and articulatory overlap with preceding [h], as proposed in previous research (Torreira 2007a, b; Parrell 2012), or if it is intended by speakers as an integral part of a series of aspirated stops, distinct from the plain voiceless stop in the Spanish consonant inventory (O’Neill 2009). In order to address this issue, we carried out a production experiment in which we manipulated speech rate and stress location, two factors known to condition the extent of coarticulation and the realization of segmental cues (Lindblom 1963, Gay 1981, Browman \& Goldstein 1990, Fourakis 1991, Moon \& Lindblom 1994, Byrd \& Tan 1996, Davidson 2006).

\subsection{Aspirated stops in Western Andalusian Spanish}

Torreira (2007a), the first phonetic study to our knowledge to investigate pre- and postaspirated stops in WAS, compared [h + voiceless stop] clusters in this dialect with [1+ voiceless stop] clusters and intervocalic voiceless stops in the same dialect and in Castilian Spanish, and additionally, with [s + voiceless stop] clusters in Castilian Spanish. It was found that both Voice Onset Time (VOT) and stop closure durations were statistically significantly longer in Western Andalusian Spanish [h + voiceless stop] clusters than in the other two segmental sequences in the same dialect, and than in all the examined segmental sequences in Castilian Spanish. Moreover, considerable variability was found in the occurrence of breathy voicing and preaspiration in WAS stops preceded by [h]. Figures 1 and 2 illustrate the realization of aspirated /s/ plus voiceless stop clusters in Western Andalusian Spanish. The example in Figure 1 exhibits a closure preceded by a very brief period of breathy voicing, and followed by a considerable period of postaspiration $(48 \mathrm{~ms})$. Figure 2 , on the other hand, displays clear periods of both pre- and postaspiration $(79 \mathrm{~ms}){ }^{1}$

In a follow-up study, Torreira (2007b) compared Western Andalusian and two other [s]aspirating dialects: Argentinean and Puerto Rican Spanish. It was found that Argentinean $[\mathrm{t}]$ and $[\mathrm{k}]$ and Puerto Rican [k] had slightly longer VOT when preceded by $[\mathrm{h}]$ than when preceded by [1] or intervocalically. However, the VOT differences in these dialects were much smaller than those found for Western Andalusian Spanish, which, moreover, were present for all three stop types. Another difference between Andalusian Spanish and the other two dialects regarded stop closure duration. Andalusian [h + voiceless stop] clusters were characterized by longer closure durations than intervocalic stops, but no lengthening of the stop closure was found for the other dialects. Finally, it was found that the duration of preaspiration before the stop closure in $[\mathrm{h}+$ voiceless stop] clusters was significantly longer in Argentinean and Puerto Rican Spanish than in Western Andalusian Spanish. It was concluded that [h + voiceless stop] clusters in Western Andalusian were produced with a great deal of gestural overlap, and that

\footnotetext{
${ }^{1}$ A reviewer notes that the stop release in Figure 2 exhibits what may be a uvular trill, probably caused by the interaction between strong aspiration and the back of the tongue for the vowel. Inspection of our materials leads us to think that this phenomenon is not recurrent.
} 

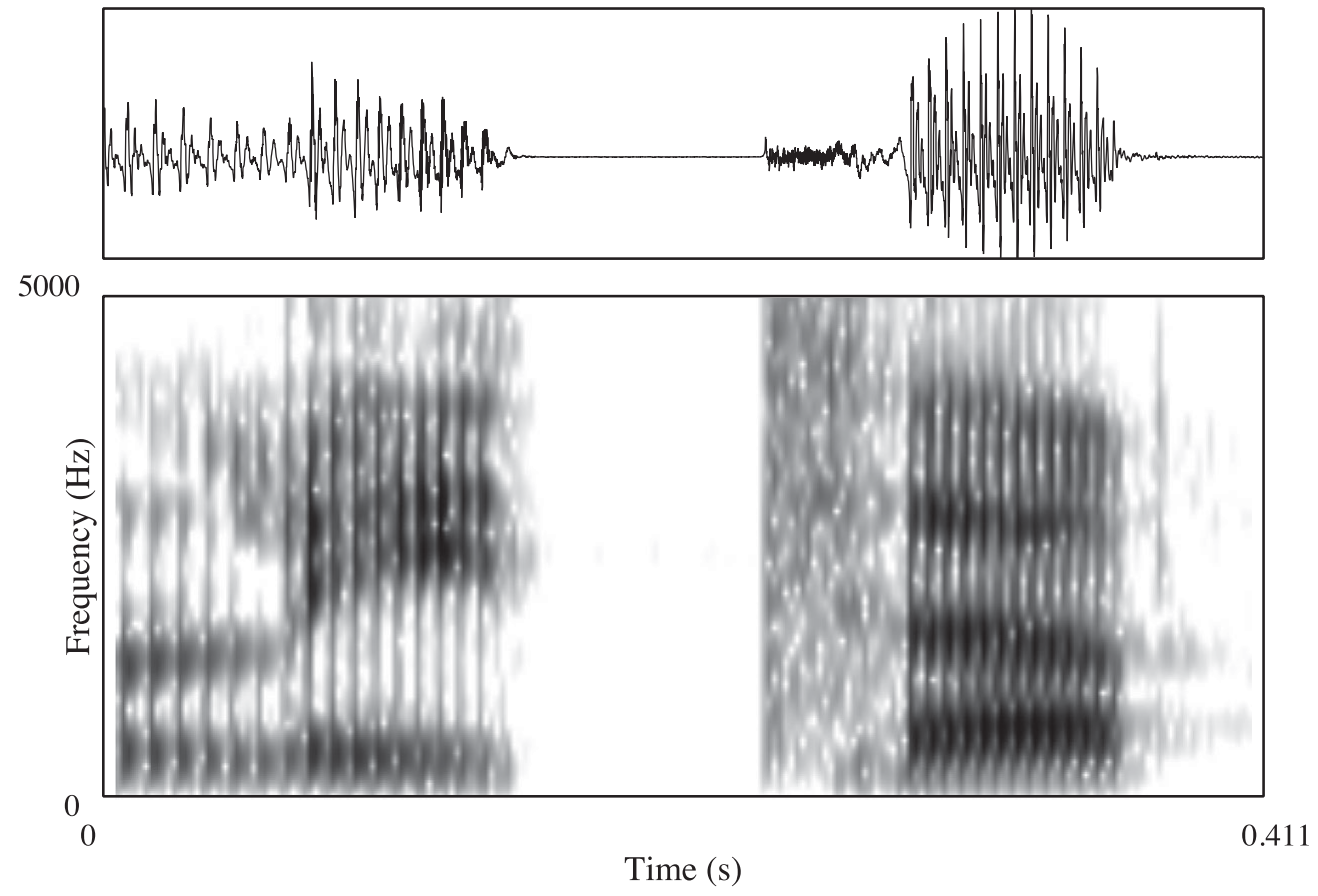

Figure 1 Word lista 'list' as pronounced by a speaker from Seville in Western Andalusia (Spain).

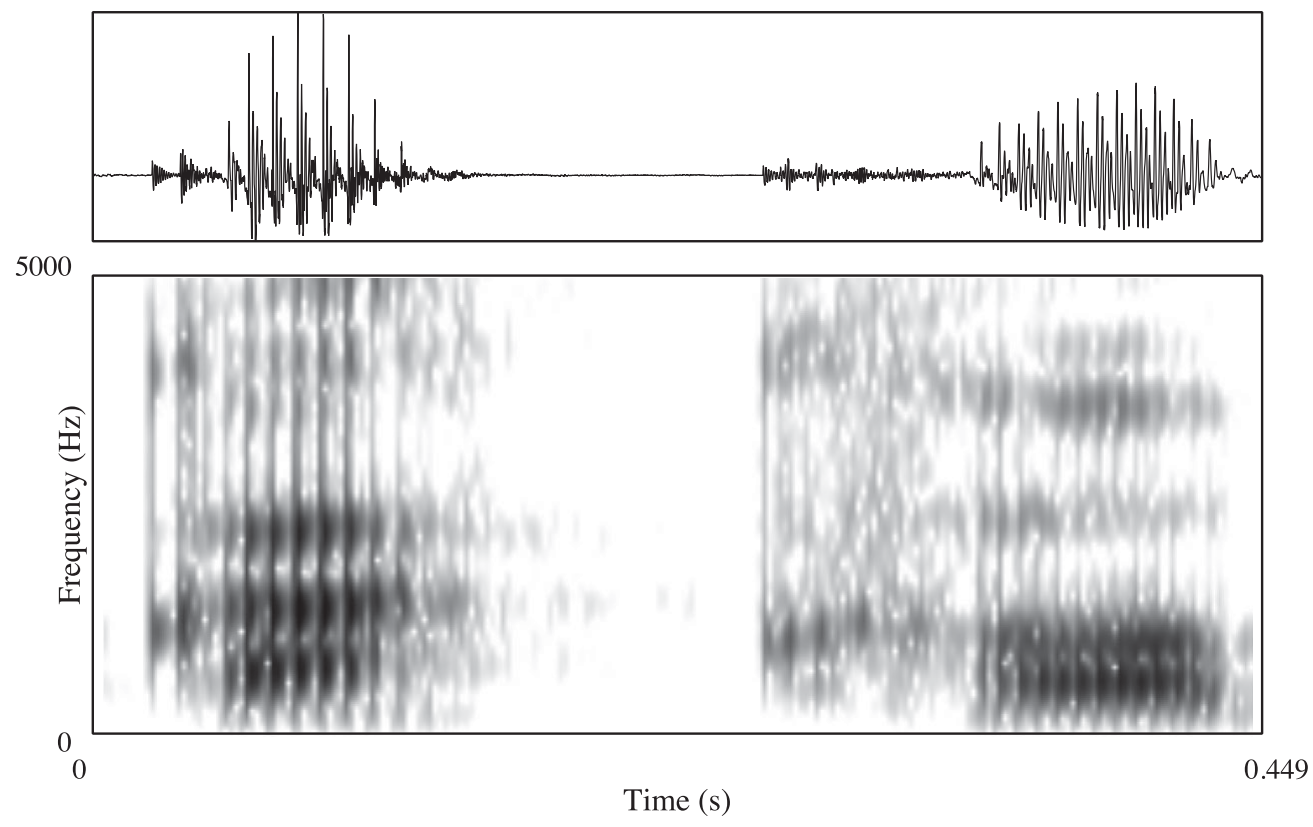

Figure 2 Word cascó 'cracked' as pronounced by a speaker from Cádiz in Western Andalusia (Spain). 


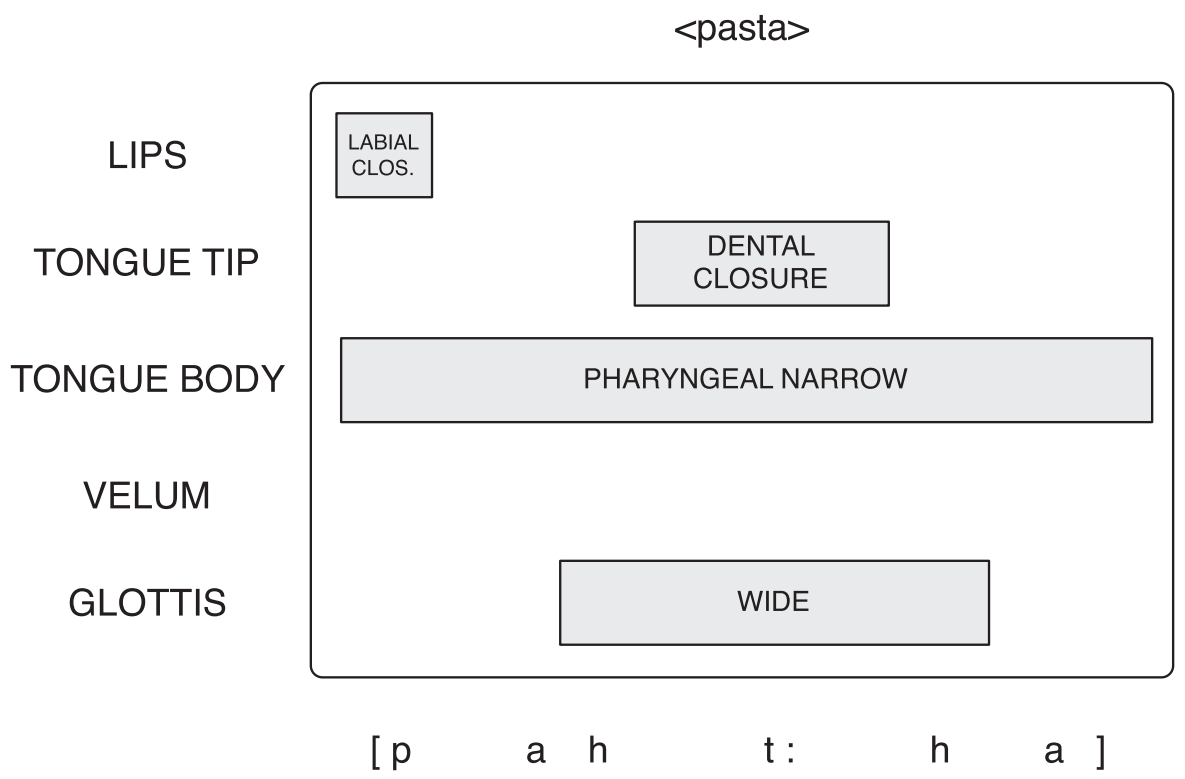

Figure 3 Hypothetical gestural score of the word pasta 'pasta' in Western Andalusian Spanish.

speakers of Argentinean and Puerto Rican Spanish produced the segments in the clusters in a more sequential manner.

\subsection{The nature of aspirated stops in Andalusian Spanish}

The two studies reviewed above showed that the realization of [ $h+$ voiceless stop] clusters with long pre- and postaspirated stop closures is a dialect-specific feature of Western Andalusian, not found in all [s] aspirating varieties of Spanish. Torreira $(2007 \mathrm{a}, \mathrm{b})$ further argued that this coarticulation pattern could not be easily dealt with in segmental terms. First, the amount of overlap between the acoustic consequences of [h] and of the following stop was such that one segment could not be properly said to precede the other. Second, the differences in the timing of oral and glottal gestures found between Western Andalusian Spanish and Argentinean and Puerto Rican Spanish were difficult to interpret in segmental terms. For these reasons, it was argued that models in which the timing of vocal tract gestures can be specified phonologically for each dialect or language (e.g. Articulatory Phonology, Browman $\&$ Goldstein 1989, 1992) were more adequate for dealing with such temporal variation than traditional segmental models.

Figure 3 shows a hypothetical gestural score for the word pasta 'pasta' in Western Andalusian. An important point in this representation is that the onset and offset of the glottal opening gesture are located before and after the tongue-tip closure corresponding to [ $\mathrm{t}]$. By retracting the glottal gesture with respect to the oral closure, a gestural score of the same word in Argentinean or Puerto Rican Spanish (which both tended to exhibit more preaspiration and less postaspiration than WAS) could be obtained without positing a segmental contrast (e.g. [hth] vs. [ht]). Such an analysis is in line with proposals that languages can differ significantly in the articulatory timing of similar segmental sequences (Browman \& Goldstein 1990, Byrd 1996, Zsiga 2000, among others).

Following work on the gestural basis of syllable structure (Browman \& Goldstein 1995, Goldstein, Byrd \& Saltzman 2006), Torreira (2007b) further hypothesized that the occurrence 
of postaspiration in WAS [hp + voiceless stop] clusters may have arisen diachronically due to a discrete shift in phasing between glottal and oral gestures, from an unstable phasing relationship across a syllable boundary (e.g. [Vh.CV]), to a more stable in-phase coordination in syllable onset position (i.e. [V.ChV]). Although this hypothesis was advanced in order to explain a diachronic change, Parrell (2012) has addressed this issue in a laboratory experiment by manipulating speech rate in WAS utterances containing an [ht] cluster, and claims to have found evidence of a switch from productions with short to long VOT as rate increased. Moreover, it is also claimed in this study that the variability observed in the elicited productions of [ht] clusters displays hallmarks of phase transitions in human coordination.

The studies reviewed above propose that the realization of [ $\mathrm{h}+$ voiceless stop] clusters in WAS results simply from a dialect-specific realignment between glottal and supraglottal gestures leading to extensive articulatory overlap. However, this interpretation seems to neglect the fact that in WAS, [h + voiceless stop] clusters consistently display longer stop closures than intervocalic stops and stops preceded by [1]. An explanation entirely based on the notion of articulatory overlap predicts that the involved gestures will be coproduced within a narrower time window, but it does not predict increases in the duration of any of the gestures. This is even more evident in cases in which the lengthened second consonant in the [hC] cluster does not share its main articulator with [h], let alone with the historical /s/. For instance, it is difficult to imagine how a delayed [h] glottal gesture in an [hp] cluster or a reduced and overlapped tongue-tip gesture in an [sp] cluster might lead to an online lengthening of the upcoming [p] closure produced at the lips.

For this reason, it could be argued that a segmental analysis of WAS [h + voiceless stop] clusters is still plausible: WAS may have developed a series of voiceless stop segments characterized by long oral closures and variable aspiration, i.e. [p:h], [t:h], [k:h]. Under this hypothesis, preaspiration could be either an additional cue of these long aspirated stops, i.e. [hp:h], [ht:h], [hk:h], as in the fortis stops of several Nordic dialects (Helgason 2002, Helgason \& Ringen 2008) and voiceless geminate stops in several Italian varieties (Stevens \& Hajek 2010), or could simply be the manifestation of the [h] segment in the consonant cluster, i.e. [hp:h], [ht:h], [hk:h]. O'Neill (2009) examined the durational patterns arising from phonological sequences consisting of a vowel, an underlying /s/, and voiceless stop consonant in WAS. It was found in this study that the duration of the complete segmental sequence was longer in cases exhibiting preaspiration than in cases displaying no preaspiration and long VOT. This was interpreted as evidence that WAS speakers sometimes collapse $[\mathrm{h}+$ voiceless stop] clusters into one single segment, an aspirated stop. This conclusion, however, must be taken with caution, since average differences between two groups of transcribed acoustic realizations do not necessarily arise, as is claimed in this study, from two distinct phonological categories. Moreover, this same study also found a trade-off between preaspiration and VOT duration on the one hand, and closure duration on the other, suggesting that variation in preand postaspiration is caused by changes in the timing of glottal and supraglottal gestures.

\subsection{Manipulating speech rate and stress placement}

One way of investigating if aspirated stops in WAS result from a coarticulatory process or from a segmental rule is to examine their behavior under changes of speech rate and stress placement. There are three reasons why manipulating these two variables can help us answer this question.

First, speech rate and stress can be expected to affect the degrees of coarticulation and articulatory overlap between segments. A substantial body of research has shown that segments produced at faster rates and unstressed syllables are more sensitive to coarticulatory effects than segments spoken at slow speech rates and in stressed syllables (Lindblom 1963, Gay 1981, Browman \& Goldstein 1990, Fourakis 1991, Moon \& Lindblom 1994, Byrd \& Tan 1996, Davidson 2006, among many others). If postaspiration in Andalusian [h + voiceless stop] clusters is caused by changes in intergestural timing, its duration can be expected to 
be longer at faster speech rates and in unstressed stop consonants. Parrell (2012) provides evidence for longer periods of postaspiration at faster speech rates, but the materials used in this study only included consonant [t], and only one carrier word. The present study intends to replicate these findings for $[\mathrm{p}]$ an $[\mathrm{k}]$, and for extended lexical materials.

Second, Kessinger \& Blumstein (1997) found that postaspiration duration (measured as Voice Onset Time) is sensitive to stress and speech rate in languages in which it is an important characteristic of voiceless stop segments. VOT in voiceless stops was longer at slow speech rates and in stressed syllables in English and Thai, but not in French. Although postaspiration in Western Andalusian Spanish is likely to play a different role than in these languages, it may still be expected to be enhanced in prosodically prominent consonants and to covary with speech rate if it is intended by speakers as part of the stop segment.

Third, if variability in the amounts of preaspiration and postaspiration around stop closures is caused by variable degrees of articulatory overlap, trade-offs between preaspiration and closure duration on the one hand, and postaspiration duration on the other, should be observed. By manipulating speech rate and stress, we hope to introduce the amounts of temporal variability necessary for these trade-offs to emerge. Parrell (2012) found evidence of a temporal tradeoff between VOT and preaspiration durations in WAS [ht] clusters spoken at different speech rates. In this study we further manipulate stress location, and also examine [hk] and [hp] clusters.

Thus, we expect that changes in speech rate and in the location of stress should help us investigate the nature of aspirated stops in WAS. The following section presents a production experiment in which these two variables were manipulated.

\section{Method}

\subsection{Speakers and materials}

Three native speakers of Western Andalusian Spanish (born and living in the town of Cádiz) participated in the study. Two of the speakers, speakers F1 and M2, had previously participated in the Torreira $(2007 \mathrm{a}, \mathrm{b})$ studies. As in those two studies, the speakers read a series of target words embedded in a carrier sentence of the type Digo X para mi' 'I say X for myself'. In the present study, the target words were selected from a set of bisyllabic verbs with infinitive forms ending in -ascar [-ahkar], -aspar [-ahpar], -astar [-ahtar]. In the case of -aspar only one existing verb (raspar 'to grate') could be used, while in the other cases three verbs were used (rascar 'to scratch', mascar 'to chew', cascar 'to crack'; pastar 'to graze', bastar 'to be enough', gastar 'to spend'). Every verb was conjugated in the first person of the present tense and third person singular of the simple past tense to obtain identical segmental sequences differing only in the placement of lexical stress (e.g. raspo ['rah.po] 'I grate' vs. raspó [rah.'po] 'he/she grated'). A total of 60 sentences were created by combining the different stop types and stress patterns ( 3 stop types $\times 2$ stress patterns $\times 10$ repetitions).

\subsection{Recording}

The recording equipment consisted of an M-Audio Firewire 410 audio interface, a laptop computer and a Shure SM10A head-mounted microphone, placed approximately $5 \mathrm{~cm}$ from the left corner of the speakers' lips. The recordings took place in a silent room in the speakers' residence.

Speakers were instructed to read the speech materials on a computer screen. Every sentence was shown on the screen separately using presentation software. The presentation slides were pseudo-randomized so that the speaker never encountered a sequence of identical sentences. The presentations were run twice, at two different speeds, yielding 120 sentences 
per speaker. In the first run, slides were changed every three seconds. In this run, speakers could read the sentences at a comfortable speech rate. In the second run, slides were changed every 1.5 seconds, forcing speakers to adopt a faster speech rate.

Since Andalusian speakers sometimes avoid dialectal phonetic traits when reading aloud (Andalusian Spanish has low prestige compared to Castilian Spanish, on which the Spanish orthography is based), we asked the speakers to read the materials as informally as possible. Perhaps because of this, or because the recordings were carried out in a relaxed atmosphere (all speakers were close acquaintances of the experimenter), only a small number of the orthographic $\langle s\rangle$ consonants in our materials were realized as sibilants $(n=12$ out of 360$)$.

A total of 360 sentences were collected ( 60 sentences $\times 2$ speech rates $\times 3$ speakers). Sentences spoken with disfluencies, incorrect target words, or a sibilant fricative were discarded. The final dataset contained 328 sentences.

\subsection{Measurements}

\subsubsection{Voice onset time}

Voice onset time (VOT) was manually measured from waveform displays. It extended from the beginning of the release of the target stop to the first visible voicing period of the upcoming vowel.

\subsubsection{Vowel duration}

Vowel duration was measured from the onset of voicing after the release of the target stop up to the beginning of the [p] closure of the word para 'for' in the carrier sentence.

\subsubsection{Closure duration}

The duration of the closure of the target stop was measured by inspecting spectrogram and waveform displays. The beginning of the stop closure was placed at the offset of energy in the F2-F3 region of the preceding segment, and the end at the release of the target stop.

\subsubsection{Preaspiration duration}

Preaspiration was defined as the stretch of signal before the target stop closure containing either breathy voicing or voiceless aspiration. All observed cases of voiceless preaspiration contained a preceding stretch of breathy voicing. The onset of preaspiration was placed when a clear drop in F2-F3 energy was observed along with the appearance of aperiodic noise. Preaspiration offset corresponded to the beginning of the stop closure.

Figure 4 illustrates the measurement scheme used in this study.

\section{Results}

We first examine the VOT values produced by the participants and assess the validity of the speech rate and stress location manipulations. We then examine the effects of speech rate and stress pattern on VOT in a series of ANOVAs. Finally, we examine trade-offs between preaspiration and closure duration and VOT via linear regression. Given the small number of speakers in the dataset, we chose to analyze the utterances of each speaker separately. For this reason, caution should be taken when interpreting the results as representative of Western Andalusian Spanish in general.

\subsection{VOT values}

We first inspected the VOT values produced by our participants. Figure 5 shows boxplots of VOT for every speaker and stop type. It can be seen from this figure that speaker M1 

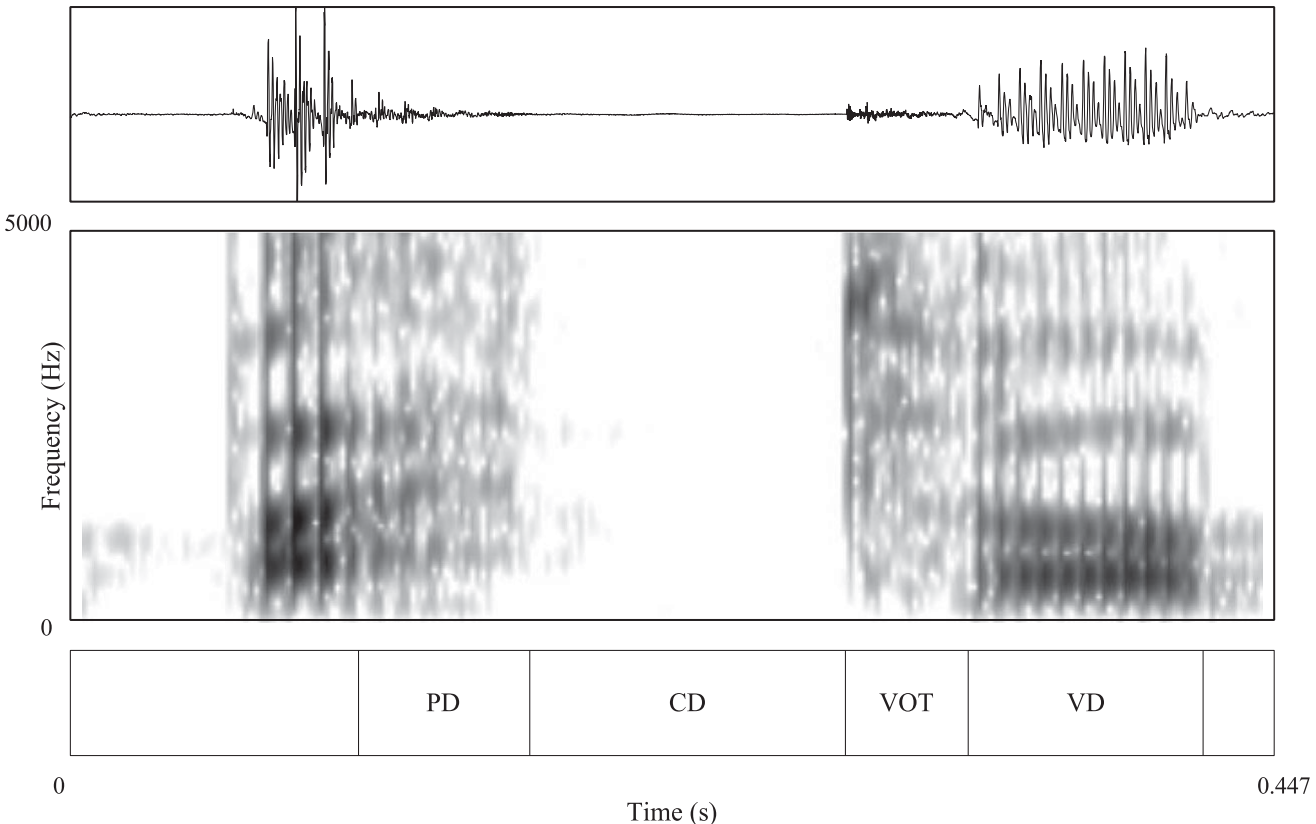

Figure 4 Sample segmentation scheme featuring the word pastó[pah.'to] 'grazed' as spoken by speaker M1. PD = preaspiration duration; $\mathrm{CD}=$ closure duration; $\mathrm{VOT}=$ Voice Onset Time; $\mathrm{VD}=$ vowel duration.

tended to produce longer VOT values than the other two speakers, particularly in the case of consonant [t]. Although the VOT values of speakers F1 and M2 tended to be shorter than those of speaker M1, they were still higher on average than those reported for Andalusian unaspirated stops in Torreira (2007a, b) (20-30 ms for [k], under $10 \mathrm{~ms}$ for [p] and 10-20 ms for $[\mathrm{t}])$. It should be noted, however, that a significant number of VOT values was rather short in comparison with the values reported for languages using postaspiration as a contrastive cue in stops (mostly above 50 ms; Lisker \& Abramson 1964, Kessinger \& Blumstein 1997, Cho \& Ladefoged 1999).

\subsection{Assessment of speech rate and stress pattern}

We then checked if speech rate and stress pattern, the two factors manipulated in the experiment, had affected the utterances of the participants as expected. In order to do this, we investigated the effects of speech rate and stress on closure and vowel duration. These two intervals are contiguous to the VOT interval that we examine in detail in the following subsections. For this reason, if no effects of rate and stress are found on closure and vowel duration, the validity of any null effect on VOT could be seriously questioned. Figures 6 and 7 show closure and vowel duration values as a function of speech rate and stress pattern. It can be seen from this figure that for all three speakers, vowel and closure durations tended to be longer in the slow speech rate and stressed conditions. This was confirmed in a series of ANOVAs with vowel and closure duration as dependent variables run separately for each speaker, in which speech rate and stress were the independent variables $(p<.01$ in all cases). 
SPEAKER F1

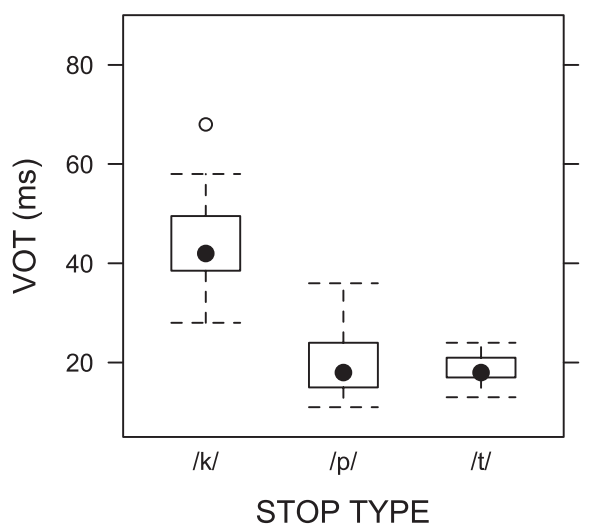

SPEAKER M1

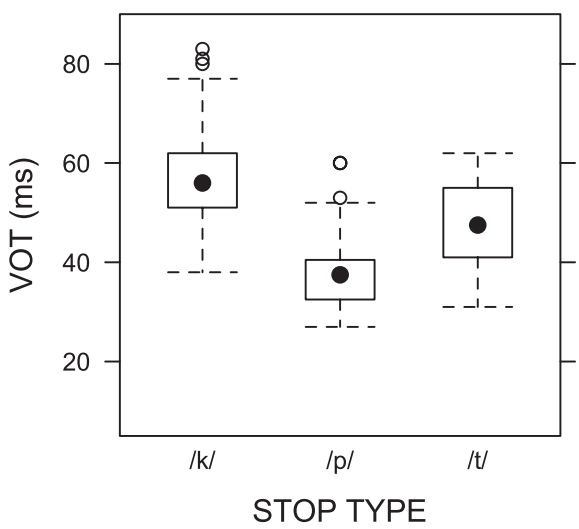

SPEAKER M2

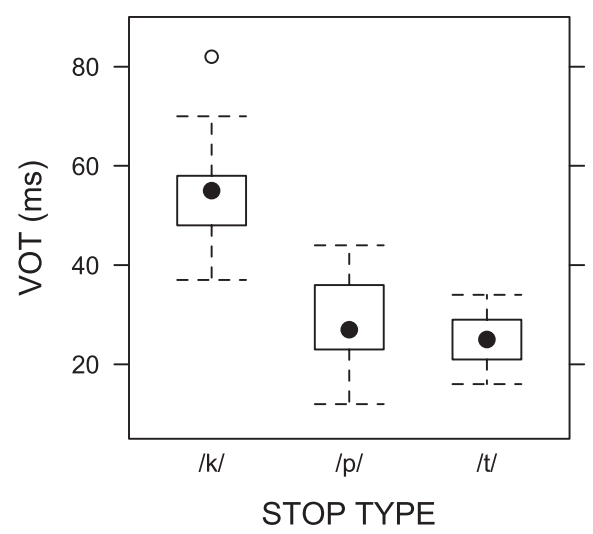

Figure 5 Boxplots of Voice Onset Time for each speaker and stop type.

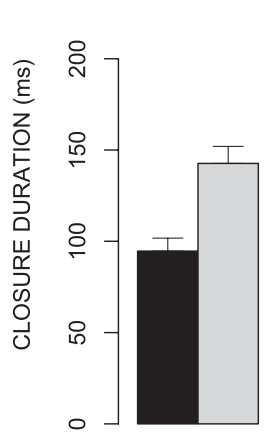

F1

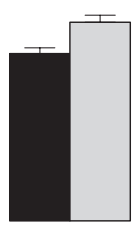

M1

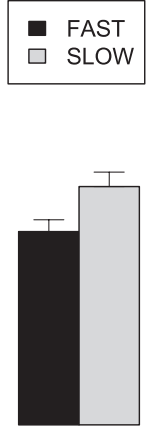

M2

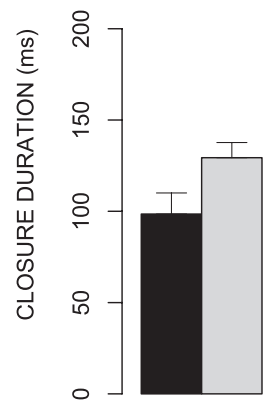

F1
- - STRESS

$\square+$ STRESS

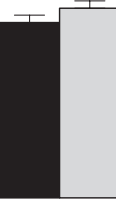

M1

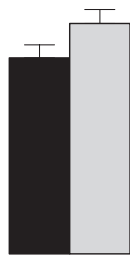

M2
SPEAKER

SPEAKER

Figure $\mathbf{6}$ Closure duration as a function of speech rate and stress pattern. Error bars include two standard errors. 


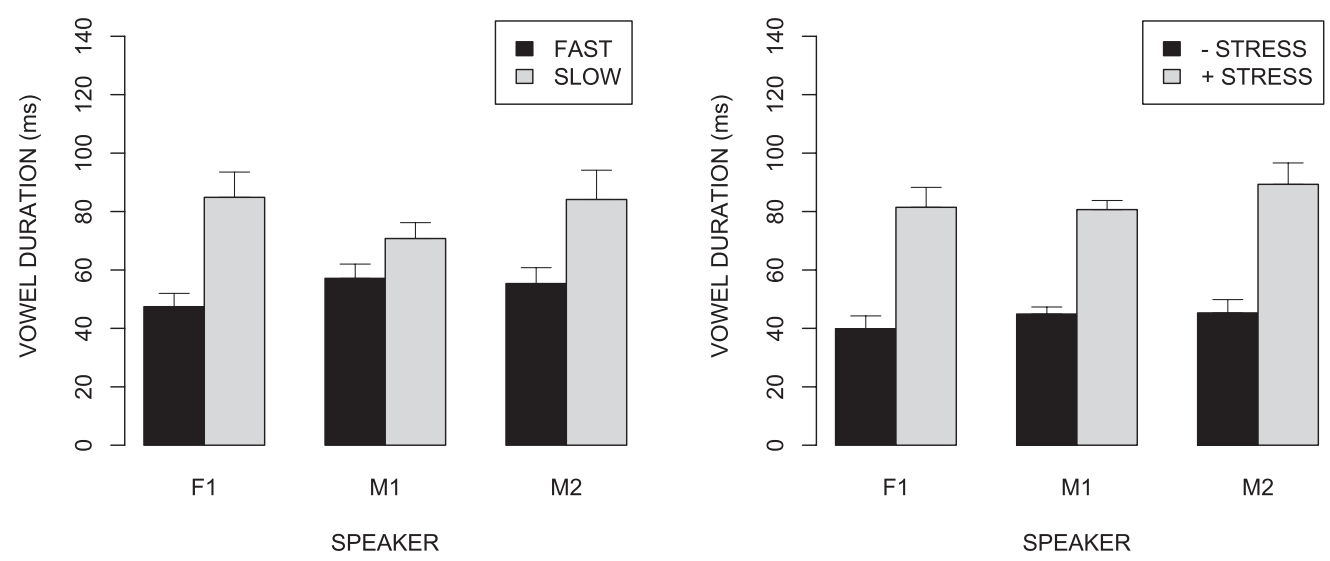

Figure 7 Vowel duration as a function of speech rate and stress pattern. Error bars include two standard errors.

Table 1 Effects of rate and stress pattern on VOT: Fand $p$ values for ANOVA analyses.

\begin{tabular}{|c|c|c|c|c|c|c|}
\hline & \multicolumn{2}{|c|}{ Speaker F1 } & \multicolumn{2}{|c|}{ Speaker M1 } & \multicolumn{2}{|c|}{ Speaker M2 } \\
\hline & $F$ & $p$ & $F$ & $p$ & $F$ & $p$ \\
\hline Stop type & 201.24 & $<.0001$ & 63.4 & $<.0001$ & 143.42 & $<.0001$ \\
\hline Rate & 2.75 & & 32.59 & $<.0001$ & 2.41 & \\
\hline Stress & 5.72 & $<.05$ & 2.97 & & 0.59 & \\
\hline Rate $\times$ Stress & 3.09 & & 12.93 & $<.0005$ & 0.05 & \\
\hline
\end{tabular}

\subsection{Effects of rate and stress on VOT}

We now examine the effects of rate and stress on VOT. If long VOT in Western Andalusian Spanish acts as an acoustic cue in a class of aspirated stops, it should be longer at slow speech rate and in stressed position than at fast speech rate and in unstressed position. Figure 8 shows VOT values as a function of speech rate and stress pattern. This figure shows that average VOT values tended to be slightly longer at slow speech rates and in unstressed syllables. In order to test for statistical significance, a series of ANOVAs with VOT as dependent variable, and speech rate and stress pattern as independent variables were run separately for each speaker. Stop type, which greatly affected VOT (see Figure 5), was included in the analyses as a covariate. The results of these analyses are summarized in Table 1 . There was a main effect of stress pattern for speaker F1. As shown in Figure 8, the VOT values of this speaker tended to be longer in the unstressed condition. An interaction between speech rate and stress pattern was found for speaker M1. VOT values for this speaker tended to be higher in the slow rate condition, but separate regression analyses of stressed and unstressed consonants revealed that the effect of speech rate on VOT was statistically significant only in unstressed syllables $(\beta=12.52, t=5.84, p<.0001)$. No other effects of speech rate or stress were found. We conclude that, in contrast with closure and vowel duration, which showed large and consistent effects of speech rate and stress, VOT did not appear to be affected by these variables in a significant way. This suggests that long VOT in Western Andalusian Spanish voiceless stops preceded by aspirated /s/ does not act as an acoustic cue of the stop consonant.

\subsection{Trade-offs between VOT and preaspiration plus closure duration}

The articulatory overlap account of long VOT in WAS voiceless stops preceded by aspirated /s/ (Torreira 2007a, b; Parrell 2012) states that variation in VOT arises from variation in the 

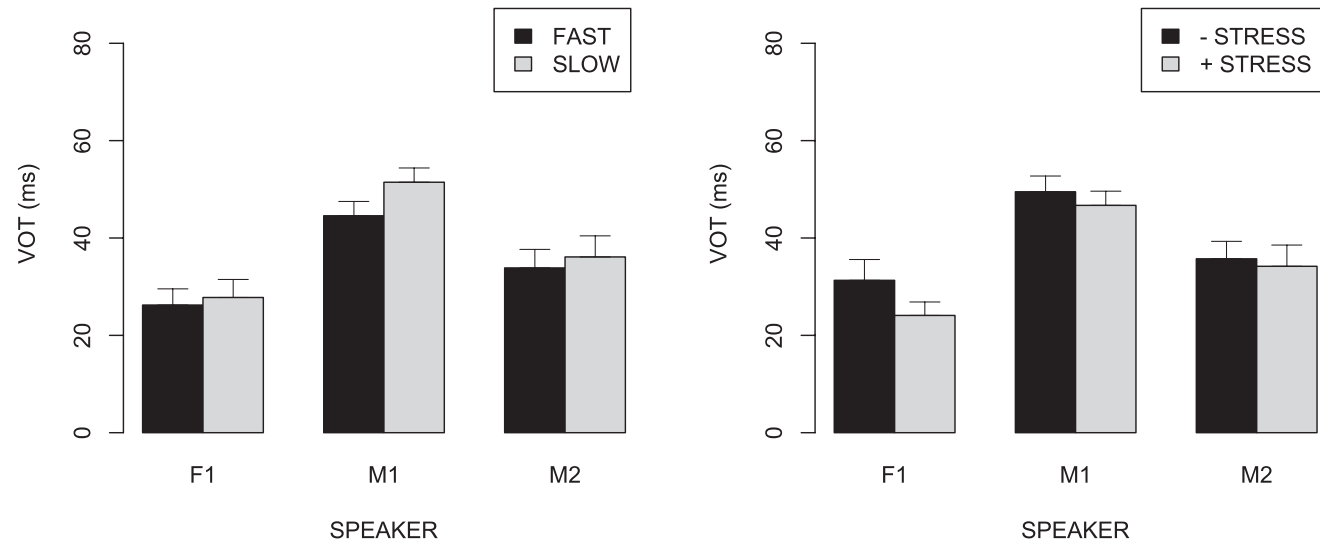

Figure 8 Voice Onset Time as a function of speech rate and stress pattern. Error bars include two standard errors.

alignment of the glottal devoicing gesture corresponding to aspirated /s/ and the supraglottal gesture corresponding the stop closure (see Section 1.3 and Figure 3 above). This predicts that long VOT values should tend to co-occur with short preaspiration and closure durations. In order to test this prediction, we looked for negative correlations between VOT on the one hand, and the sum of preaspiration and closure duration on the other. As in all analyses presented in the previous section, each speaker was analyzed separately.

We first fitted regression models predicting VOT with preaspiration plus closure duration. Statistically negative correlations between these two variables were observed for speaker F1 and M2 (speaker F1: $\beta=-0.07, t=-3.07, p<.005$; speaker M2: $\beta=-0.23, t=-5.2$, $p<.0001)$. In the case of speaker M1, a negative trend similar in size to that of speaker F1 was found, but statistical significance was not achieved $(\beta=-0.08, t=-1.55, p=.12)$. These findings are illustrated in Figure 9, which plots VOT as a function preaspiration plus closure duration.

We then examined if negative correlations between VOT and preaspiration plus closure duration could also be observed after controlling for the different factors manipulated in the experiment. In order to do this, we fitted regression models with VOT as the dependent variable, speech rate, stress and stop type as covariates, and preaspiration plus closure duration as the main predictor. In this case, all three speakers showed statistically negative relationships between VOT and preaspiration plus closure duration (speaker F1: $\beta=-0.12, t=-5.01$, $p<.0001$; speaker M1: $\beta=-0.12, t=-2.01, p<.05$; speaker M2: $\beta=-0.14, t=-3.08$, $p<.0005)$.

Thus, the regression results in this section reveal a quite consistent negative relationship between VOT on the one hand and preaspiration and closure duration on the other. In our view, this negative correlation meets the predictions of the coarticulatory account of the occurrence of postaspiration in WAS voiceless stops.

\section{Discussion}

The present study has investigated the nature of Western Andalusian Spanish aspirated stops by subjecting them to variation in speech rate and stress pattern. Our rationale was that if postaspiration in WAS voiceless stops is intended by speakers as a part of the stop segment, its duration should be longer in stressed than in unstressed syllables. On the other hand, if it is primarily a coarticulatory phenomenon, it should be shorter in stressed syllables than 
Speaker F1

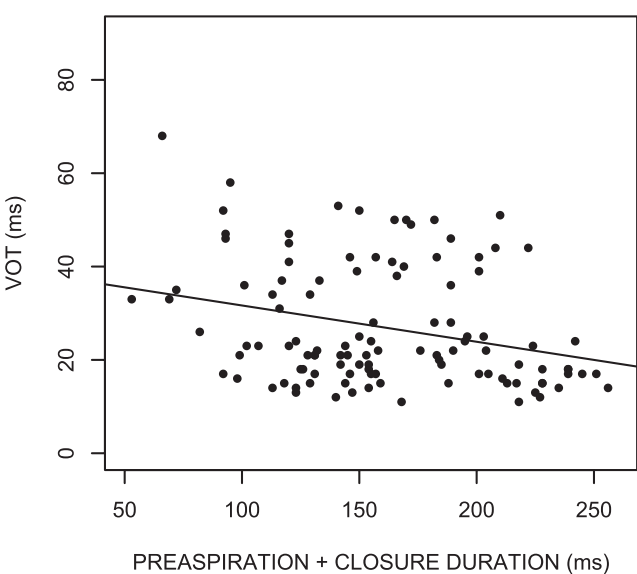

Speaker M1

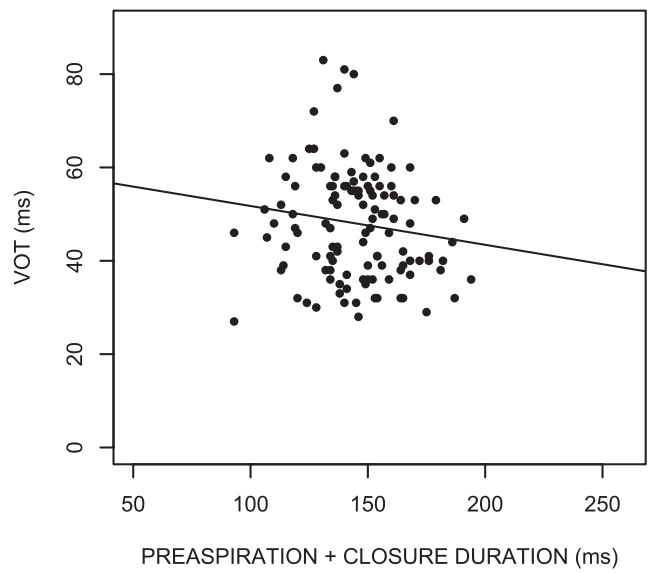

Speaker M2

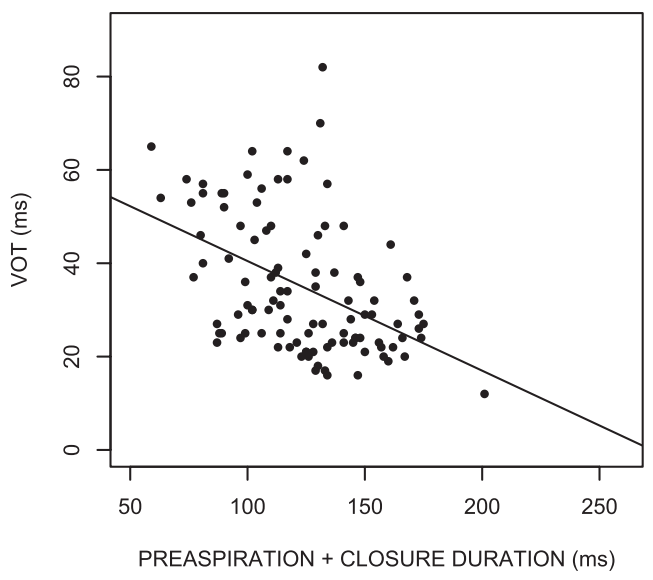

Figure $\mathbf{9}$ Voice Onset Time as a function of preaspiration plus closure duration for each speaker.

in unstressed syllables. Similarly, if it is an intended cue for the stop segment, it should be negatively correlated with speech rate (longer VOT at slower speech rates), as observed in languages such as Thai and English (Kessinger \& Blumstein 1997), while if it arises from increased coarticulation, a positive correlation should be observed. Moreover, if postaspiration is primarily a coarticulatory phenomenon, trade-offs should be observed between VOT on the one hand, and preaspiration and closure durations on the other. Our results have shed some light on this issue.

First, stops produced at slower speech rates presented only slightly longer mean VOT values than stops spoken at fast speech rates, and statistical significance was only reached for the unstressed stops of one of the three speakers. This contrasts with the results of Kessinger \& Blumstein (1997), who found that VOT in English and Thai voiceless stops was consistently adjusted by speakers along changes in speech rate. Second, stressed stops did not show longer VOT than unstressed stops for any speaker. In fact, we found that one speaker exhibited the opposite trend. Again, this contrasts with the findings of Kessinger \& 
Blumstein (1997) for Thai and English. Second, in agreement with a coarticulatory account of postaspiration in WAS voiceless stops, we found statistical evidence of trade-offs between VOT and preaspiration and closure durations. Interestingly, these trade-offs were observed clearly for two of the three speakers in simple linear models including only the main predictor, and for all speakers when the factors manipulated in the experiment (i.e. stop type, speech rate, stress pattern) were controlled for. In general, these results argue against the existence of a class of voiceless stop segments in WAS for which postaspiration would act as an important cue. In line with previous proposals (Torreira 2007a, b; Parrell 2012), it rather seems that postaspiration in WAS [h + voiceless stop] clusters is the result of extensive articulatory overlap between $[\mathrm{h}]$ and upcoming voiceless stops. Still, it should be noted that no consistent increase in articulatory overlap was observed along increases in speech rate, and in unstressed vs. stressed conditions. One possible reason why this is so is that in WAS [ $\mathrm{h}+$ voiceless stop] clusters, the glottal and supraglottal gestures may be phased very closely even in conditions in which we would not expect much articulatory overlap, hence the lack of significant effects of speech rate and stress location on VOT.

An account relying on articulatory overlap is therefore able to explain variation in preand postaspiration in WAS [h + voiceless stop] clusters, as well as the observed differences between WAS and other/s/-aspirating dialects. However, there is an aspect of these clusters that cannot be accounted for solely by the notion of articulatory overlap: previous studies have shown that the closures of WAS voiceless stops are longer when preceded by [h] than when preceded by a vowel, or another consonant such as [1] (Torreira 2007b); also, these closures appear to be consistently longer than those of analogue [ $\mathrm{h}+$ voiceless stop] clusters in other Spanish dialects (Torreira 2007a). As pointed out in the introduction, increased articulatory overlap predicts that the glottal devoicing gesture and the supraglottal closure gesture should be coproduced within a narrower time window (leading to variation in preand postaspiration), but it does not predict a lengthening of the supraglottal closure gesture.

Interestingly, as noted in the introduction, lengthening has been said to occur in WAS for several consonants whenever they are preceded by aspirated /s/ (i.e. voiced stops, nasals, laterals and voiceless fricatives; see Rodríguez-Castellano \& Palacio 1948, Alarcos Llorach 1958, Zamora Vicente 1969, Mondéjar 1991, Romero 1995a). Although some of these consonants have been referred to as geminates without direct traces of the articulation of a glottal gesture corresponding to [h] (e.g. los monos [lom:ono] 'the monkeys', los libros [lol:ißro] 'the books'), our own observations of this dialect have often revealed breathy phonation in the transition between the vowel and the geminate consonant. This could be taken as evidence of a glottal gesture corresponding to [h], which, as in the case of voiceless stops, is produced in overlap with the supraglottal gestures of the upcoming consonants. These observations, along with the findings of the present and previous studies of $[\mathrm{h}+$ voiceless stop] clusters, suggest that the wide range of phonetic realizations exhibited by different [hC] clusters could be produced by two gestural mechanisms:

1. Realignment of the [h] devoicing gesture with respect to the onset of the supraglottal gesture in upcoming consonants. This gestural realignment mechanism leads WAS voiceless stops, but not their Argentinean or Puerto Rican counterparts, to often display long periods of postaspiration when preceded by [h].

2. Lengthening of the supraglottal gesture in upcoming consonants. Consonants in WAS, but not in Argentinean and Puerto Rican Spanish, are lengthened when preceded by aspirated $/ \mathrm{s} /$. Since this lengthening and the realignment mechanism discussed above co-occur in WAS, but are not observed in other /s/-aspirating dialects, it seems reasonable to posit a connection between them. One possibility is that this lengthening mechanism has arisen to compensate for the realignment of [h] with respect to upcoming consonants, as a means of preserving the prosodic properties of the affected syllable.

Articulatory research on different sorts of [hC] clusters is needed to determine if the two gestural mechanisms proposed above can explain the typologically unusual phonetic 
phenomena exhibited by WAS (e.g. pre- and postaspirated voiceless stops, long voiced fricatives, breathy nasal and lateral geminates). Ideally, such research should employ more speakers than the present study, so that more powerful and generalizable statistical analyses are possible. Moreover, since the occurrence of /s/-aspiration is known to be conditioned by sociolinguistic factors, a fact potentially leading to unnatural realizations of $[\mathrm{hC}]$ clusters in the lab, materials elicited in a more informal setting (e.g. spontaneous conversations among friends) are necessary to complement experimental results.

\section{Conclusion}

The present work has shown that the period of postaspiration in Western Andalusian Spanish aspirated /s/ plus voiceless stop clusters reported by previous studies is not a robust cue for a hypothetical series of aspirated stop segments. Rather, its variability and behavior under changes of speech rate and stress location rather indicate that it is the result of extensive articulatory overlap. Since this kind of articulatory overlap occurs in WAS, but not in other /s/-aspirating dialects studied, we conclude that it results from a dialect-specific mechanism governing the coordination between glottal and supraglottal gestures in $[\mathrm{h}+$ voiceless stop clusters].

We have also hypothesized that the lengthening exhibited by WAS voiceless stops when preceded by $[\mathrm{h}]$ is caused by a different gestural mechanism applicable to all WAS [hC] clusters in general. Further research is needed to address this hypothesis.

From a more general perspective, the findings and arguments presented here lend support to the idea that intergestural coordination patterns are learned by speakers as part of their dialect or language.

\section{Acknowledgements}

I would like to thank Jessamyn Schertz, José Ignacio Hualde, Adrian Simpson, and three anonymous reviewers for their comments and help.

\section{References}

Alarcos Llorach, Emilio. 1958. Fonología y fonética: a propósito de las vocales andaluzas. Archivum 8, 191-203.

Browman, Catherine P. \& Louis Goldstein. 1989. Articulatory gestures as phonological units. Phonology 6(2), 201-251.

Browman, Catherine P. \& Louis Goldstein. 1990. Tiers in Articulatory Phonology, with some implications for casual speech. In John Kingston \& Mary E. Beckman (eds.), Papers in Laboratory Phonology 1: Between the grammar and the physics of speech, 341-376. Cambridge: Cambridge University Press.

Browman, Catherine P. \& Louis Goldstein. 1992. Articulatory phonology: An overview. Phonetica 49, $155-180$.

Browman, Catherine P. \& Louis Goldstein. 1995. Gestural syllable position effects in American English. In Fredericka Bell-Berti \& Lawrence J. Raphael (eds.), Producing speech: Contemporary issues for Katherine Safford Harris, 19-33. New York: American Institute of Physics.

Byrd, Dani. 1996. Influences on articulatory timing in consonant sequences. Journal of Phonetics 24(2), 209-244.

Byrd, Dani \& Cheng C. Tan. 1996. Saying consonant clusters quickly. Journal of Phonetics 24(2), 263-282.

Cho, Taehong \& Peter Ladefoged. 1999. Variation and universals in VOT: Evidence from 18 languages. Journal of Phonetics 27(2), 207-229. 
Davidson, Lisa. 2006. Schwa elision in fast speech: Segmental deletion or gestural overlap? Phonetica 63, 79-112.

Fourakis, Marios. 1991. Tempo, stress, and vowel reduction in American English. Journal of the Acoustical Society of America 90(4), 1816-1827.

Gay, Thomas. 1981. Mechanisms in the control of speech rate. Phonetica 38(1-3), 148-158.

Goldstein, Louis, Dani Byrd \& Elliot Saltzman. 2006. The role of vocal tract gestural action units in understanding the evolution of phonology. In Michael A. Arbib (ed.), From action to language: The mirror neuron system, 215-249. Cambridge: Cambridge University Press.

Helgason, Pétur. 2002. Preaspiration in the Nordic languages: Synchronic and diachronic aspects. Ph.D. dissertation, Stockholm University.

Helgason, Pétur \& Catherine Ringen. 2008. Voicing and aspiration in Swedish stops. Journal of Phonetics $36,607-628$.

Hualde, José Ignacio. 2005. The sounds of Spanish. Cambridge: Cambridge University Press.

Kessinger, Rachel H. \& Sheila H. Blumstein. 1997. Effects of speaking rate on voice-onset time in Thai, French and English. Journal of Phonetics 25, 143-168.

Lindblom, Björn. 1963. Spectrographic study of vowel reduction. Journal of the Acoustical Society of America 35(11), 1773-1781.

Lipski, John M. 1994. Latin American Spanish. London: Longman.

Lisker, Leigh \& Arthur S. Abramson. 1964. A cross-language study of voicing in initial stops: Acoustical measurements. Word 20, 384-422.

Mondéjar, José. 1991. Dialectología andaluza. Granada: Editorial Don Quijote.

Moon, Seung-Jae \& Björn Lindblom. 1994. Interaction between duration, context, and speaking style in English stressed vowels. Journal of the Acoustical Society of America 96, 40-55.

O'Neill, Paul. 2009. The effect of s-aspiration on occlusives in Andalusian Spanish. Oxford University Working Papers in Linguistics, Philology \& Phonetics 12, 73-86.

Parrell, Benjamin. 2012. The role of gestural phasing in Western Andalusian Spanish aspiration. Journal of Phonetics 40(1), 37-45.

Rodríguez-Castellano, Lorenzo \& Adela Palacio. 1948. Contribución al estudio del dialecto andaluz: el habla de Cabra. Revista de Dialectología y Tradiciones Populares 4, 347-428.

Romero, Joaquín. 1995a. Gestural organization in Spanish: An experimental study of spirantization and aspiration. Ph.D. dissertation, University of Connecticut.

Romero, Joaquín. 1995b. An articulatory view of historical s-aspiration in Spanish. In Carol A. Fowler (ed.), Haskins Laboratories status report on speech research, vol. 119, 255-266. New Haven, CT: Haskins Laboratories.

Stevens, Mary \& John Hajek. 2010. Post-aspiration in Standard Italian: Some first cross-regional acoustic evidence. The 11th Annual Conference of the International Speech Communication Association (Interspeech 2010), 1557-1560. Makuhari, Japan.

Torreira, Francisco. 2007a. Pre- and post-aspirated stops in Andalusian Spanish. In Pilar Prieto, Joan Mascaró \& Maria-Josep Solé (eds.), Prosodic and segmental issues in Romance, 67-82. Amsterdam: John Benjamins.

Torreira, Francisco. 2007b. Coarticulation between aspirated-s and voiceless stops in Spanish: An interdialectal comparison. The 9th Hispanic Linguistics Symposium, 113-120. Somerville, MA: Cascadilla Press.

Zamora Vicente, Alonso. 1969. Dialectología española, 2nd edn. Madrid: Gredos.

Zsiga, Elizabeth. 2000. Phonetic alignment constraints: Consonant overlap and palatalization in English and Russian. Journal of Phonetics 28, 69-102. 